\title{
INFLUENCE OF DIFFERENT ROTARY SYSTEMS ON THE AMOUNT OF APICALLY EXTRUDED DEBRIS IN MANDIBULAR MOLARS (AN IN VITRO STUDY)
}

\author{
Sherif Adel El Khodary* and Nehal Nabil Roshdy*
}

\begin{abstract}
Objective: The aim of the study was to compare and evaluate Hyflex CM files and M-Pro files versus Protaper Next files regarding the amount of apically extruded debris in the mesial root canals of mandibular molars.

Methodology: Sixty three human permanent mandibular molars were utilized in the study. Empty Eppendorf tubes were weighed using an analytical balance three times and an average weight was calculated (W1). Then, a hole was created in the stopper of the Eppendorf tubes and mesial roots were inserted. The roots were randomly assigned into 3 groups according to the instrumentation technique used: Group I: Protaper Next $(n=21)$, Group II: Hyflex $(n=21)$ and Group III: M-Pro $(n=21)$. Distilled water was used as an irrigant in all groups. After instrumentation, the vials were placed in an incubator for 3 days and the apically extruded debris collected in the Eppendorf tubes were weighed again (W2) after instrumentation. Welch test was used for comparison between the three groups.
\end{abstract}

Results: There was no statistically significant difference between the amount of debris extrusion of the three groups $(\mathrm{P}=0.204)$.

Conclusion: Within the limitation of this study it was concluded that all systems were associated with extrusion of debris.

\section{INTRODUCTION}

Preparation of the root canal system is one of the most fundamental procedures in endodontic treatment. Its main purpose is to achieve thorough shaping and cleaning of the root canal followed by profound apical and lateral hermetic seal. However, extrusion of infective material into the perirapical tissues remains an inherent problem associated with the shaping and cleaning procedures, since identified by Chapman et al., (1968). Where, the periapical reaction can be initiated by physical or chemical irritation that may disrupt the integrity of peri-radicular tissues. ${ }^{(1,2)}$ The debris extrusion during root canal treatment procedures causes

\footnotetext{
* Lecturer in Endodontics, Faculty of Dentistry, Cairo University
} 
interappointment flare-ups and postoperative pain which is considered an undesirable occurrence both for the patient and the practitioner. ${ }^{[3]}$

None of the current preparation techniques can prepare root canals without debris extrusion, however the amount of debris extruded may vary according to the preparation technique and file system used. ${ }^{(3,4)}$

Dr. John McSpadden introduced NiTi instruments to the market in (1992) ${ }^{(5)}$. Their uniqueness was attributed to their flexibility, super elasticity and the ability to maintain the original canal anatomy. Recent studies have shown that the amount of apically extruded debris may vary according to different factors; the type of the file system ${ }^{(6)}$, the chosen preparation techniques ${ }^{(7)}$, the effects of instrument design, such as radial lands, different taper, flute designs, materials used and movement of the instrument ${ }^{(8-10)}$ and the degree of canal curvature AEJ

ProTaper Next (PTN) (Dentsply Maillefer, Ballaigues, Switzerland) is a fifth-generation nickel titanium system with an off-centred rectangular cross- section. The PTN system is composed of three instruments made of a unique NiTi alloy (M-wire) manufactured through a thermal treatment process and incorporates a variable taper design and a unique offset mass of rotation, thereby improving the strength and flexibility along its active part. ${ }^{(11)}$

HyFlex Controlled Memory (CM) (ColteneWhaledent, Altst€atten, Switzerland) is a NiTi rotary system manufactured through a unique thermal process that controls the material's memory (12). CM wire is created by thermally treating the NiTi wires to shift the austenite/martensite transition temperature at about $50{ }^{\circ} \mathrm{C}$ so that a stable martensitic microstructure occurs at mouth temperature. The HyFlex CM instruments show greater flexibility when compared with conventional NiTi instruments ${ }^{(13)}$.

On the other hand, M-Pro rotary system is a recently introduced 3 files system which has high fracture resistance, high adaptability to root canal curvatures and also the files can be pre-curved. The files have a convex triangular cross- section.

The aim of our study was to compare and evaluate Hyflex CM files and M-Pro files versus Protaper Next files regarding the amount of apically extruded debris in mesial root canals of human permanent mandibular molars. The null hypothesis of the study was that there would be no significant difference among the different systems for root canals preparation regarding the amount of apically extruded debris.

\section{MATERIALS AND METHODS}

\section{Sample size calculation:}

Based on Kocak et al.(2015) ${ }^{(14)}$ on using power $80 \%$ and $5 \%$ significance level, 21 sample per group would be sufficient. The sample size was calculated by $\mathrm{G}$ power program.

\section{1- Teeth selection:}

Freshly extracted human permanent mandibular molars due to prosthodontics or periodontal disease problem were collected from the clinic of the department of oral and maxillofacial surgery, Faculty of Dentistry, Cairo University. Initial radiographs were performed to ensure that all the samples had two separate canals in the mesial root with two apical foramina with no calcification, root fracture, cracks and/or internal resorption. External root surfaces were cleaned from adherent tissues and hard deposits using ultrasonic scaling then disinfected by sodium hypochlorite for 30 minutes and stored in saline solution .for use

\section{2- Preparation of samples}

\section{Procedural steps}


Occlusal surface of the mandibular molars was flattened using TR-12 tapered stone with round end under water coolant.

Hemi-sectioning of teeth at the furcation level into mesial and distal roots was done using a lowspeed diamond saw under water Isomet 1000. Access cavity was prepared on the extracted mandibular molars using diamond round bur and Endo-Z bur in a high-speed handpiece under water spray cooling.

The canal patency was checked by placing size $15 \mathrm{~K}$-file (Mani, Japan) into the canals until it was visible at the apical foramen. Canals that did not allow placement of size 15 file to the apex and those wider than size 20 file at the apex were excluded. Only samples canal curvature between 0-10 degrees according to Schneider's method ${ }^{[15]}$ were selected. The working length (WL) was determined by passing K-file size \#10 through the apical foramen and then withdrawing it for $1 \mathrm{~mm}$.

\section{3- Grouping of samples}

Mesial roots were numbered, equally and randomly assigned into 3 groups: Group I: Protaper Next ( $\mathrm{n}=21)$, Group II: M-Pro ( $\mathrm{n}=21)$ and Group III: Hyflex $(n=21)$ for evaluation of apically extruded debris.

\section{4- Method of evaluation:}

A modified version of the experimental model described by Myers and Montgomery ${ }^{(16)}$ (Fig 1) was used to evaluate apically extruded debris. Empty Eppendorf tubes were sterilized, numbered and weighed using an analytical balance three times and average weight was calculated (W1). Then, a hot instrument was used to create a hole in the stopper of the Eppendorf tubes. External root surface was covered with two layers of nail polish except for $1 \mathrm{~mm}$ around the apical foramen. Mesial root was inserted into these holes under pressure and a 27-gauge bent needle was inserted alongside the stopper to balance the air pressure. The whole apparatus was then assembled into a glass vial and the vial was covered with aluminum foil. After instrumentation and irrigation, separated stopper with the mesial root were removed from the pre-weighed Eppendorff tube, the external root surface was flushed with $1 \mathrm{~mL}$ distilled water to collect debris adhering to external root surface. Then, the vials were placed in the incubator at $650^{\circ}$ C for 3 days with placement of Calcium Chloride inside the incubator to ensure moisture removal. The apically extruded debris collected in the preweighed Eppendorf tubes were weighed again (W2) after instrumentation and evaporation of moisture and irrigant. The amount of apically extruded debris was determined by subtracting the average weight of the pre-weighed Eppendorf tubes from the average weight of Eppendorf tubes containing

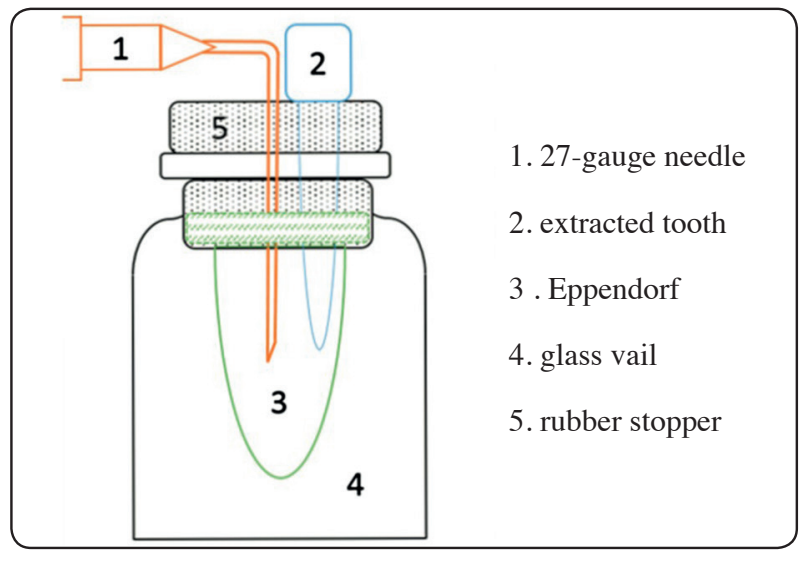

Fig. (1): Assembly and schematic diagram for evaluation of apically extruded debris

the dried debris obtained from three consecutive measurements (W2 -W1). All measurements were done using analytical balance (sartorius).

\section{5- Root canal preparation}

Group I ProTaper Next (n=21): Mesial root canals were prepared using ProTaper Next in ProTaper mode with the sequence X1 (Size 17, 0.04 taper) to $1 / 2$ of the working length at $300 \mathrm{rpm}$ with a torque of $4 \mathrm{Ncm}$. X2 (Size 25, 0.06 taper) and X3 (Size 30, 0.07 taper) to the full working length. 
All the Protaper Next instruments were used at 300 rpm with a torque of $4-5.2 \mathrm{Ncm}$ according to the manufacturer instructions.

Group II Hyflex ( $n=21)$ : Mesial root canals were prepared using HyFlex CM. HyFlex instruments proceeded in the canals at speed $500 \mathrm{rpm}$ with torque $2.5 \mathrm{Ncm}$ with sequence file (Size 25-0,08) as orifice opener, file (Size 20-0,04) and file (Size 25-0,06) for full working length according to the manufacturer instructions.

Group III M-Pro (n=21): Mesial root canals were prepared using M-Pro (according to manufacturing instructions). Coronal flaring was performed with the M-Pro opener (18-0.09) at speed $500 \mathrm{rpm}$ and torque $3 \mathrm{~N} . \mathrm{cm}$. Then preparation of the canal to the full working length was done by M-Pro 200.04 followed by M-Pro 250.06 at $500 \mathrm{rpm}$ and torque $1.5 \mathrm{~N} . \mathrm{cm}$ according to the manufacturer instructions.

The X-Smart Plus micro-motor (Dentsply Maillefer, Ballaigues, Switzerland), operated the three rotary systems following the manufacturer instructions. The root canals were irrigated with $1 \mathrm{~mL}$ of distilled water between each successive file with 30-gauge needle tips (NaviTip, Ultradent, South Jordan, UT, USA) $2 \mathrm{~mm}$ short from the working length. Then, the canals were irrigated with $1 \mathrm{~mL}$ of distilled water as a final rinse.

\section{Statistical analysis:}

Data were tested for normality using Kolmogrov Smirnov test and Shapiro Wilk test and were tested for homogeneity of variances using Levene's test. Based on the previous finding Welch test was selected for comparison between the three groups.

\section{RESULTS}

Protaper Next group showed the least mean and SD weight of debris $(0.03 \pm 0.001)$ followed by the Hyflex group as $(0.005 \pm 0.005)$, while the highest mean was attributed to M-Pro group (0.006 \pm 0.005$)$. However, there was no statistically significant difference between the amount of debris extrusion of the three groups $(\mathrm{P}=0.204)$. Table (1), Fig 2.

TABLE (1): Mean, standard deviation (SD) and results of Welch test for comparison of the weight of debris formed by the three file systems:

\begin{tabular}{|c|c|c|c|c|}
\hline & $\begin{array}{c}\text { Protaper } \\
\text { Next }\end{array}$ & Hyflex & M-Pro & P-Value \\
\hline Mean & 0.003 & 0.005 & 0.006 & 0.204 \\
\hline SD & 0.001 & 0.005 & 0.005 & \\
\hline
\end{tabular}

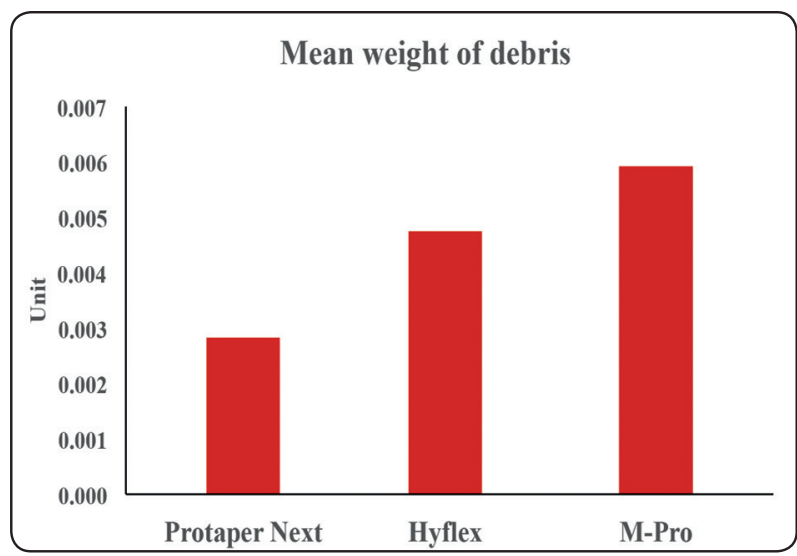

Fig. (2): Bar chart representing the mean weight of debris formed by the three file systems

\section{DISCUSSION}

The aim of the present study was to compare and evaluate ProTaper Next files versus Hyflex CM files and M-Pro files regarding the amount of apically extruded debris of mesial root canals of permanent mandibular molars. A common problem that encounter practitioners during root canal treatment, is the debris extrusion to the peri-radicular region during the instrumentation procedure, causing inter treatment flare-up and a persistent periapical inflammation ${ }^{(17) .}$ 
All the instruments selected were engine-driven as Beeson et al (1998) $)^{(\mathbf{1 8})}$ stated that the enginedriven techniques extruded reduced amounts of debris. The rotary motion, tends to direct debris toward the orifice, avoiding its compaction in the root canal, whereas utilizing the crown-down technique improve instrument control during preparation of the apical third of the canal. ${ }^{(19,20)}$

At the present study, ProTaper Next rotary file system was used as the control group since the design of its apical portion and its off-centered rectangular cross section lead to the removal of debris in the coronal direction and result in less debris extrusion as concluded by Ozsu ${ }^{(21)}$ in 2014, Kocak ${ }^{(14)}$ in 2015 and Cicek ${ }^{(22)}$ in 2016.

On the other hand, the other two rotary file systems, HyFlex CM and M-Pro were selected as they possess greater flexibility when compared to conventional Ni-Ti instruments. They also provide superior flexibility and enable the instruments to maintain original canal curvature as well as increasing efficiency and safety during instrumentation.

Aiming to provide real life conditions, natural teeth were used rather than simulated artificial canals in our study which has different micro-hardness in comparison to the root dentin. Consequently, heat generation produced during instrumentation affects the instrument's cutting blades. In the current study, lower molars were selected because they are associated with higher incidence of post-endodontic pain. The enrolled mesial root canals of mandibular had mild to moderate curvature for closer in vivo circumstances and to present greater challenge to instrumentation (Yesilsoy 1988) ${ }^{(23)}$, (Alonso 2012) $)^{(24)}$ and (labbaf 2017) ${ }^{(25)}$.

The final apical preparation diameter was set at size 25 for all the tested groups for standardization purpose which is an essential requirement for comparison of debris extrusion of different root canal instruments. ${ }^{(26)}$
Since the method of debris collection and its weighing is very critical, in all the experimental groups, distilled water was used as an irrigant as it has no solvent effect so, the extrusion of debris depends only on the mechanical action of the instruments. Also, the use of $\mathrm{NaOCl}$ irrigant leads to sodium crystallization phenomenon which may cause possible weight increase affecting the result of this study. ${ }^{[58]}$ Then, the debris collected in the vials were heated until the distilled solution was completely dried off to completely eliminate the moisture, which might increase the weight of specimens as mentioned by Fairboum et al (1987). ${ }^{(27)}$

Rotary nickel-titanium (Ni-Ti) instruments elaborated a variety of designs including non-cutting tips, radial lands, different cross sections and varying tapers aiming to improve the working efficiency. In the present study, all of the rotary systems; ProTaper Next, Hyflex and the M-pro systems work in rotational motion behavior, however, they possess different design features which may cause different amounts of apically extruded debris ${ }^{(29)}$.

HyFlex CM and MPro rotary systems present the recent metallurgy technology presented as the $\mathrm{CM}$ wire which contains a smaller percentage of nickel than other systems ${ }^{(30)}$. The reduction in the nickel content creates a metal that is softer, i.e., exhibits lower hardness and less tendency for canal transportation due to its control memory behavior. ${ }^{(31)}$. The CM wires developed to provide superior flexibility, enabling the instruments to maintain the original canal anatomy as well as increasing efficiency and safety during instrumentation. Where, control memory file systems (CM wire) have less cutting efficiency than that of Protaper Next shape memory file system (M wire) which results in less debris collected in the apical area with less possibility of debris extrusion during preparation. ${ }^{(32,33,34)}$ This could be explained by the fact that the shape memory files as Protaper Next tend to return to its original posture (straight) regardless the shape of the canal causing undue 
removal of dentin of the apical area with much debris extrusion. ${ }^{(35)}$

Kocak et al ${ }^{(28)}$ in 2016 and Labbaf ${ }^{(25)}$ in 2017 demonstrated that Hyflex files produced less debris extrusion as, unwinding the spirals of HyFlex rotary system occurs during instrumentation. This phenomenon may lead to decrease in the cutting cleaning ability of the instrument. As a result, production of the dentinal chips and debris were decreased. Diemer and Calas (2004) ${ }^{(36)}$ who compared the effect of pitch length and stated that the increasing variable pitch decreases the tendency to screw in and also reduces the helical angle which in turn reduces the apical extrusion, Also Koch and Brave (2002) ${ }^{(37)}$ stated that files with constant helical angle allow debris to accumulate and varying the helical angle enhances removal of debris more efficiently.

Contradicted with Surakanti et al in $2014^{(38)}$ which could be due to different incubation period where the eppendorf tubes were incubated at $37^{\circ} \mathrm{C}$ for 15 days, while we incubated them for $68^{\circ} \mathrm{C}$ for 5 days. Also, Nevares et al in $\mathbf{2 0 1 5}{ }^{(39)}$, who utilized a different type of irrigant solution $(\mathrm{NaOCl})$ which might result in sodium crystallization phenomenon. Another reason for contradiction with Ehsani et al in $\mathbf{2 0 1 6}^{(\mathbf{4 0 )}}$ may be due to the use of different teeth, mandibular premolars instead of Mandibular $1^{\text {st }}$ molars used in the present study

\section{REFERENCES}

1- Tanalp J. and Güngör T.: Apical extrusion of debris: a literature review of an inherent occurrence during root canal treatment. International endodontic journal, 47(3): 211-221, 2014

2- Kustarci A, Akdemir N, Siso SH and Altunbas D.: Apical extrusion of intracanal debris using two engine driven and step-back instrumentation techniques: An in vitro study. Eur J Dent; 2:233-9, 2008.

3- Siqueira J.: Microbial causes of endodontic flareups. International Endodontic Journal. 36(7): 453-63, 2003.

4- Souza R.: The importance of apical patency and cleaning of the apical foramen on root canal preparation. Brazilian Dental Journal. 17: 6-9, 2006.
5- Haapasalo M. and Ya S.: Evolution of nickel-titanium instruments: from past to future. Endodontic topics. 29(1): 3-17, 2013.

6- Capar ID, Arslan H, Akcay M and Ertas H.: An in vitro comparison of apically extruded debris and instrumentation times with ProTaper Universal, ProTaper Next, Twisted File Adaptive, and HyFlex instruments. J Endod; 40: 1638-41, 2014.

7- De-Deus G, Neves A and Silva EJ.: Apically extruded dentin debris by reciprocating single-file and multifile rotary system. Clin Oral Investig; 19: 357-61, 2015.

8- Kocak S, Kocak MM, Saglam BC, Teurker SA, Sagsen B and Er O.: Apical extrusion of debris using self-adjusting file, reciprocating single-file, and 2 rotary instrumentation systems. J Endod; 39: 1278-80, 2013.

9- Burklein S and Schafer E.: Apically extruded debris with reciprocating single-file and full-sequence rotary instrumentation systems. J Endod; 38: 850-2, 2012.

10- Burklein S, Benten S, and Schafer E.: Quantitative evaluation of apically extruded debris with different single-file systems: reciproc, F360 and OneShape versus Mtwo. Int Endod J; 47: 405-9, 2014.

11- Uygun A., Kol E., Topcu M.K., Seckin F., Ersoy I. and Tanriver M.: Variations in cyclic fatigue resistance among ProTaper Gold, ProTaper Next and ProTaper Universal instruments at different levels. Int Endod J;1-6, 2015.

12- Gutmann J. and Gao Y.: Alteration in the inherent metallic and surface properties of nickel-titanium root canal instruments to enhance performance, durability and safety: a focused review. International Endodontic Journal. 45(2): 113-128, 2012.

13- Gambarini G., Plotino G., Grande N., Al-Sudani D., Luca M., Testarelli L.: Mechanical properties of nickel-titanium rotary instruments produced with a new manufacturing technique. International Endodontic Journal. 44(4): 337 $341,2011$.

14- Kocak M., Cicek E., Kocak S., Saglam B. and Yilmaz N: Apical extrusion of debris using ProTaper Universal and ProTaper Next rotary systems. International endodontic journal. 48(3): 283-286, 2015.

15- Schneider SW. A comparison of canal preparations in straight and curved root canals. Oral Surg Oral Med Oral Pathol Oral Radiol Endo. (32): 271-275, 1971. 
16- Myers G. and Montgomery S.: A comparison of weights of debris extruded apically by conventional filing and Canal Master techniques. Journal of Endodontics. 17: 275-9, 1991.

17- Iqbal M., Kurtz E., and Kohli M.: Incidence and factors related to flare ups in a graduate endodontic programme. International endodontic journal. 42(2): 99-104, 2009.

18- Beeson T., Hartwell G., Thornton J. and Gunsolley J.: Comparison of debris extruded apically in straight canals: conventional filing versus profile. 04 Taper series 29. Journal of endodontics. 24(1):18-22, 1998.

19- Kuştarcı A., Akpınar K. and Kürşat Er.: Apical extrusion of intracanal debris and irrigant following use of various instrumentation techniques. Oral Surgery, Oral Medicine, Oral Pathology, Oral Radiology, and Endodontology. 105(2): 257-262, 2008.

20- Goerig A., Michelich R. and Schultz H.: Instrumentation of root canals in molar using the step-down technique. Journal of Endodontics. 8(12): 550-554, 1982.

21- Ozsu D., Karatas E., Arslan H., Topcu M.: Quantitative evaluation of apically extruded debris during root canal instrumentation with ProTaper Universal, ProTaper Next, WaveOne, and self-adjusting file systems. European journal of dentistry, 8(4): 504-508, 2014.

22- Çiçek E., Akkocan O. and Furuncuoglu F.: Comparison of apically extruded debris associated with several nickeltitanium systems after determining working length by apex locator. Journal of conservative dentistry. 19(1): 68, 2016.

23- Yesilsoy C., Koren L., Morse D., Rankow H., Bolanos O. and Furst M. (1988): Post-endodontic obturation pain: a comparative evaluation. Quintessence International. 19(6): 431-438, 1988.

24- Alonso- Ezpeleta L., Gasco-Garcia C., Castellanos Cosano L., Gonzalez M., Lopez - Ftias F. and Segura -Egea J.: Postoperative pain after one visit root-canal treatment on teeth with vital pulps: comparison of three different obturation techniques. Medicine Oral Pathology Oral Circulation Buccal. 17(4): 721-727, 2012.

25- Labbaf H., Moghadam K., Shahab S., Bassir M. and Fahimi M.: An In vitro Comparison of Apically Extruded Debris Using Reciproc, ProTaper Universal, Neolix and Hyflex in Curved Canals. Iranian endodontic journal. 12(3): 307, 2017.
26- Peters O.: Current challenges and concepts in the preparation of root canal systems: a review. Journal of endodontics 30(8): 559-567, 2004.

27- Fairbourn D., McWalter G. and Montgomery S.: The effect of four preparation techniques on the amount of apically extruded debris. Journal of endodontics. 13(3): 102-108, 1987.

28- Koçak, M., Cicek E., Kocak S., Saglam B. and Furuncuoglu F.: Comparison of ProTaper Next and HyFlex instruments on apical debris extrusion in curved canals. International endodontic journal. 49(10): 996-1000, 2016.

29- Logani A. and Shah N.: Apically extruded debris with three contemporary Ni-Ti instrumentation systems: An ex vivo comparative study. Indian Journal of Dental Research. 19(3): 182, 2008.

30- Zinelis S, Eliades T, Eliades G.: A metallurgical characterization of ten endodontic $\mathrm{Ni}-\mathrm{Ti}$ instruments: assessing the clinical relevance of shape memory and superelastic properties of $\mathrm{Ni}-\mathrm{Ti}$ endodontic instruments. International Endodontic Journal. 43(2): 125-34, 2010.

31- Gao Y., Gutmann J., Wilkinson K., Maxwell R. and Ammon D.: Evaluation of the impact of raw materials on the fatigue and mechanical properties of ProFile Vortex rotary instruments. Journal Endodontics. 38(3): 398-401, 2012.

32- Türker S.A., Uzunoğlu E. and Aslan M.H. (2015): Evaluation of apically extruded bacteria associated with different nickel-titanium systems. Journal of endodontics. 41(6): 953-955, 2015.

33- Shah S., Borkar A. and Vishwajit B.: Apical extrusion of debris and irrigant using neolix and one-shape rotary systems: a comparative study International Journal of Recent Scientific Research. 7(5):11325-11327, 2016.

34- Arslan H., Karatas E., Ismail D.c., Ozsu D. and Doganay E.: Effect of protaper universal, endoflare, revo-S, hyflex coronal flaring instruments, and gates glidden drills on crack formation. Journal of Endodontics, 40(10): 1681$1683,2014$.

35- Ashraf F., Shankarappa P., Misra A., Sawhney A., Sridevi N. and Singh A.: Stereomicroscopic Evaluation of Dentinal Cracks at Different Instrumentation Lengths by Using Different Rotary Files (ProTaper Universal, ProTaper Next, and HyFlex CM): An Ex Vivo Study. Scientifica (Cairo). Article ID: 8379865, 7 pages, 2016. 
36- Diemer F. and Calas P.: Effect of pitch length on the behavior of rotary triple helix root canal instruments. Journal Endodontics. 30: 716-8, 2004.

37- Koch K. and Brave D.: Real world Endo: Design features of rotary files and how they affect clinical performance. Oral Health. 92: 39-49, 2002.

38- Surakanti J., Venkata R., Vemisetty H., Dandolu R., Jaya N. and Thota S.: Comparative evaluation of apically extruded debris during root canal preparation using ProTaper $^{\mathrm{TM}}$, Hyflex $^{\mathrm{TM}}$ and Waveone ${ }^{\mathrm{TM}}$ rotary systems. Journal of conservative dentistry. 17(2): 129, 2014.
39- Nevares G., Romeiro k., Albugueraue D., Xavier F., Fogal H., Freire L. and Cunha R.: Evaluation of Apically Extruded Debris during Root Canal Retreatment Using ProTaper Next and Reciproc in Severely Curved Canals. Iranian endodontic journal. 12(3): 323, 2017.

40- Ehsani M., Farhang R., Harandi A., Tavanafar S., Raoof M., and Galledar S.: Comparison of Apical Extrusion of Debris by Using Single-File, Full-Sequence Rotary and Reciprocating Systems. Journal of dentistry (Tehran, Iran). 13(6): 394, 2016. 